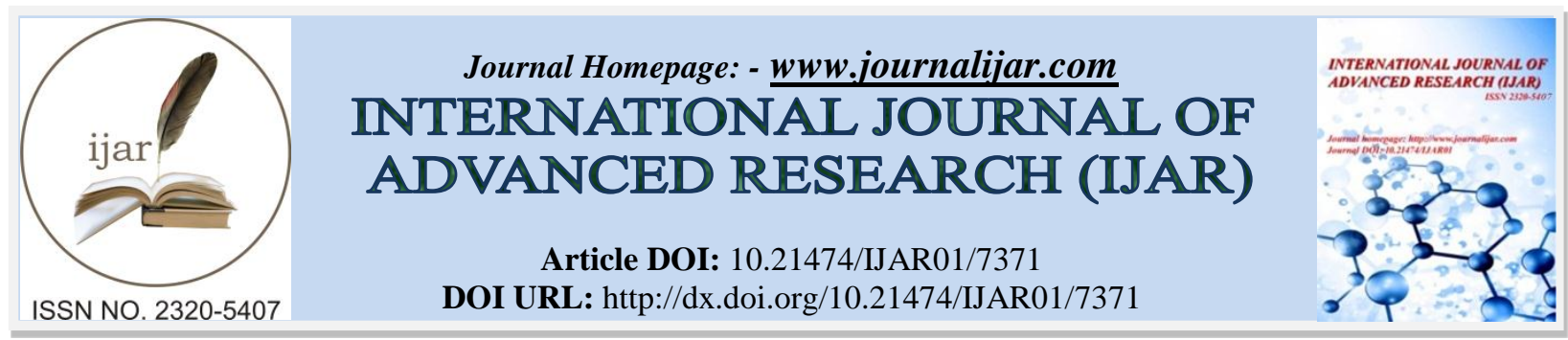

RESEARCH ARTICLE

\title{
NEW CASE OF CONRADI HUNERMANN SYNDROME IN A NEWBORN MALE.
}

Kaoutar Imrani, Othman Ayouche and Rachida Dafiri.

Radiology Department, Children's Hospital, Mohamed V University, Rabat, Morocco.

\section{Manuscript Info}

Manuscript History

Received: 08 May 2018

Final Accepted: 10 June 2018

Published: July 2018

Keywords:-

Conradi Hunermann Male X-ray

Epiphyseal calcification.

\begin{abstract}
Chondrodysplasia punctata type 2, also known as Conradi-HunermannHapple syndrome, is a rare genetic disorder. This disorder is characterized by bone, skin and eye abnormalities.It occurs almost exclusively in females as it is usually lethal in males before birth. We report a new original observation of a newborn full term male, presenting a facial dysmorphism and skeletal abnormalities. X-rays showed bilateral symmetrical punctate calcifications of femoral, tibial, fibular and ankle epiphyses. The diagnosis of X-linked chondrodysplasia punctata type 2 (CDX2) has been suggested and confirmed by biochemical study and molecular analysis. This case is important as it is a milestone for further future research.
\end{abstract}

Copy Right, IJAR, 2018,. All rights reserved.

\section{Introduction:-}

Chondrodysplasia punctata type 2, also known as Conradi-Hunermann-Happle syndrome, is a rare genetic disorder. Its incidence is poorly known. It is a bone dysplasia inherited in an $\mathrm{X}$ linked dominant mode[1, 6, 7]. It occurs almost exclusively in females (95\% of cases), as it is usually lethal in males before birth [2]. This disorder is characterized by bone, skin and eye abnormalities. Imaging is essential and shows epiphyseal punctate calcifications, which is the most characteristic sign of the disease [3-5]. We report a new original observation of Conradi-Hunermann-Happle syndrome in a newborn male.

\section{Case report:-}

A 5 days full term male presented with facial dysmorphism and skeletal abnormalities.

On physical examination, the patient had axial hypotonia, hypertelorism, low ear implantation, postaxial polydactyly on the left hand, hypoplasia of the fifth left finger, unequal lengths of the lower limbs and erythematous squamous plaques on the lower limbs.

X-rays showed bilateral symmetrical punctate calcifications of femoral, tibial, fibular and ankle epiphysis (Figure 1).The punctate calcifications have also been found in the vertebrae, the iliac bones, the sacrum and the coccyx. (Figure 2).

The diagnosis of X-linked chondrodysplasia punctata type 2 (CDX2) has been suggested and confirmed by biochemical study and molecular analysis which showed respectively an elevation in serum 8 dehydrocholesterol, and a missense mutation heterozygous exon 2 of the EBP gene. 
The patient was lost to follow up.

\section{Discussion:-}

Chondrodysplasia punctata type 2 or Conradi- Hünermann -Happle syndrome, is a rare genetic disorder. It is a bone dysplasia transmitted in an X-linked dominant mode (CDPX2). It occurs almost exclusively in girls (95\% are cases).[2] . It is usually lethal in the male fetus[2, 4]. Our observation is original by its occurrence in a newborn male.

Genetically, CDPX2 is due to a mutation of the gene emopamil binding protein (EBP ) located on the short arm of the $\mathrm{X}$ chromosome.This gene codes for a protein involved in the biosynthesis of cholesterol, the 3-betahydroxysteroid-delta (8) -delta (7) -isomerase.

Clinically, the signs are usually apparent at birth, but identified in adult age in the imperfect forms .The disease usually associate bone, eye and skin symptoms [4].There are actually different varieties of clinical forms.

Females are characterized by a development delay and an original facies with a forehead bulging, nasal bridge flattening and sparse eyelashes and eyebrows. Contrary to males who have a facial dysmorphism: hypertelorism, telecanthus, micrognathism, prominence of the nasal bridge, low ear implantation, and a broad anterior fontanel.

The most characteristic skeletal abnormalities of CDPX2 are punctuated calcifications of the long bones, vertebrae, cartilages, ribs epiphyses and trachea. The principal differential diagnosis are 18-trisomia, 21-trisomia, foetal alcoolopathy, breast lupus and warfarin or phenytoin uptake during pregnancy[1,6].

Other bone radiological signs include an asymmetric arthritis, shortening members, post-axial Polydactyly and scoliosis [4].

Dermatological manifestations represent an important diagnosis barrier.They are usually associated with bone and eye signs. However, some observations of isolated dermatological expression have been reported. The absence of ophthalmological or bone signs does not exclude the diagnosis of CDPX2 which is the case for our observation.

Knowledge of cutaneous forms is paramount and the histological study is essential for diagnosing CDPX2. The skin lesions are characterized by their bilateralism and symmetry. The patients present an anichthyosic appearance at birth with thick scales of Blashko-linear disposition, cicatricle alopecia, and follicular hyperkeratosis and nail dystrophies [5]

Ocular abnormalities are common in CDPX2.They are dominated by cataracts, microphthalmia, strabismus or glaucoma can also be found .[4,5]

Other malformations may be encountered during CDPX2. They represent less than $10 \%$ of cases. We may find congenital heart defects, kidney malformations, deafness or central nervous system malformations including Dandy Walker variant and corpus callosum agenesis found mainly in male subjects. In boys hypospadias or cryptorchidism can also be found [4].

Mental retardation is observed in male subjects, whereas intelligence is not affected in girls $[4,5]$.

The treatment is multidisciplinary. It consists of specific treatments tailored to each case (dermatological, orthopedic, etc.).Genetic counseling and prenatal diagnosis should be offered to families.

\section{Conclusion:-}

Hünermann Conradi syndrome is a rare genetic disorder affecting almost exclusively females .It combines bone, ophthalmic and dermatological signs. Imaging is the milestone for diagnosis. The punctate epiphyseal calcification is the most characteristic bone abnormalities of this disease. Molecular analysis confirms the diagnosis by showing the EBP gene mutation. We described a rare male viable case of Hünermann Conradi syndrome as it is important for further future research. 


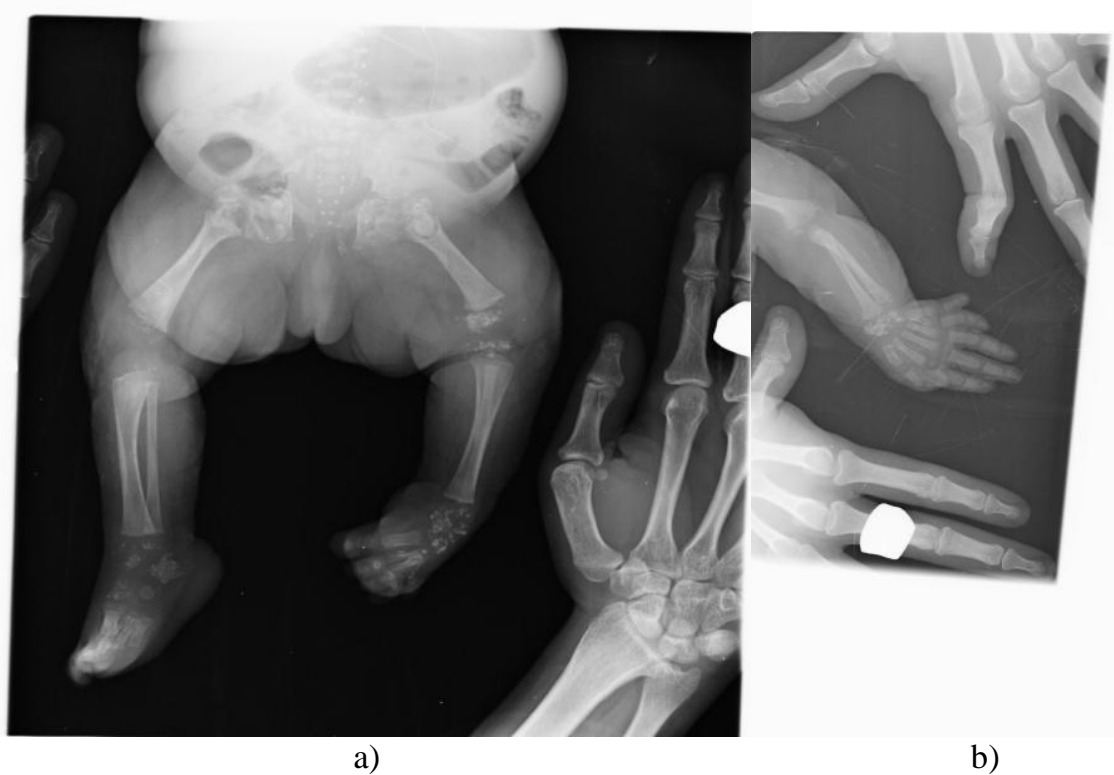

Figure 1 :-a)lower limbs X-ray showing micromelia of lower left limb with epiphyseal tibial, femoral and tarsal punctuated calcifications .b) Left hand X-ray showing a post axial hexadactyly,a brachymesophalangy of the fifth finger and epiphyseal calcifications of the humerus, the radius, the ulna and the carpal bones.
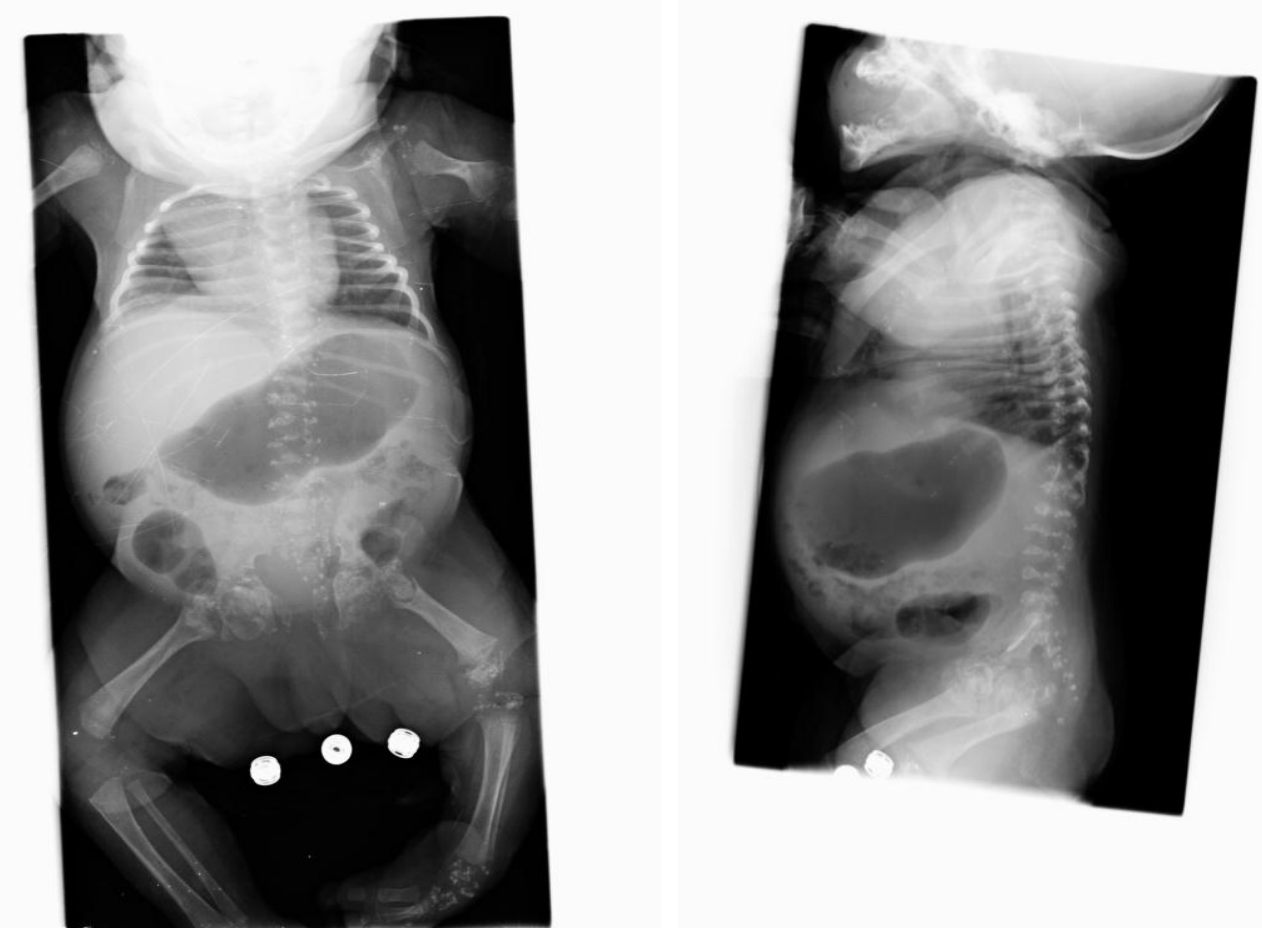

Figure 2:-Spine and pelvis X-ray showing scoliosis with right convexity and punctate calcifications in the epiphyseal cartilage of the spine, cartilage in Y, sacrum and coccyx. 


\section{References:-}

1. Benaicha A, Dommergues M, Jouannic J, Jacquette A, Alexandre M, Le Merrer M, et al. Prenatal diagnosis of brachytelephalangic chondrodysplasia punctata: case report. Ultrasound in Obstetrics and Gynecology. 2009;34(6):724-6.

2. Dempsey MA, Tan C, Herman GE. Chondrodysplasia Punctata 2, X-Linked. In: Adam MP, Ardinger HH, Pagon RA, Wallace SE, Bean LJH, Stephens K, et al., editors. GeneReviews((R)). Seattle (WA): University of Washington, Seattle. GeneReviews is a registered trademark of the University of Washington, Seattle. All rights reserved.; 1993.

3. Hello M, David A, Barbarot S, editors. Syndrome de Conradi-Hünermann-Happle de disposition unilatérale. Annales de dermatologie et de vénéréologie; 2010: Elsevier.

4. Hosoya M, Kanzaki S, Wakabayashi S, Ogawa K. Tympanoplasty for chondrodysplasia punctata: Case report. Auris Nasus Larynx. 2017;44(5):616-9.

5. Lefebvre M, Dufernez F, Bruel AL, Gonzales M, Aral B, Saint-Onge J, et al. Severe X-linked chondrodysplasia punctata in nine new female fetuses. Prenatal diagnosis. 2015;35(7):675-84.

6. Omobono E, Goetsch W. Chondrodysplasia punctata (the Conradi-Hünermann syndrome). A clinical case report and review of the literature. Minerva pediatrica. 1993;45(3):117-21.

7. Sanfilippo A, Bartoletti S. Brachytelephalangic chondrodysplasia punctata: A difficult diagnosis. Radiology case reports. 2010;5(1). 